\title{
Las preguntas de Susi. Algunas carencias en la Formación Inicial
}

\section{Susi's questions. Some gaps in initial teacher education}

\author{
Carmen Díez Navarro ${ }^{1}$
}

Recibido: 08 de julio de 2019 Aceptado: 17 de julio 2019 Publicado: 31 de julio de 2019

To cite this article: Díez Navarro, M. C. (2019). Las preguntas de Susi. Algunas carencias en la Formación Inicial.

Márgenes, Revista de Educación de la Universidad de Málaga, o (0), 106-109

DOI: http://dx.doi.org/10.24310/mgnmar.voio.6612

\section{ORCID $\quad{ }^{1}$ Mari Carmen Díez Navarro \\ Maestra de Educación Infantil y psicopedagoga \\ http://carmendiez.com}

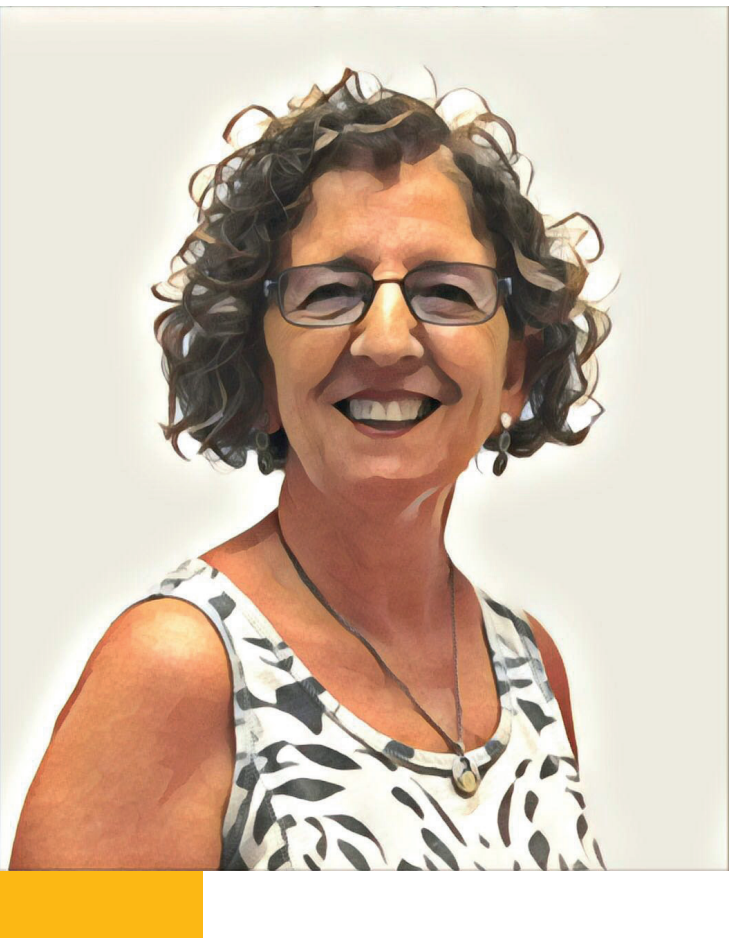

\section{RESUMEN}

Como es bien sabido, la formación inicial es algo importante y transformador para los futuros maestros, aunque puede recorrerse yendo hacia adelante, de una manera abierta al cambio y generadora de innovación, o mirando hacia atrás, repitiendo prácticas del pasado que ofrecen la seguridad de lo conocido, pero no el avance de lo nuevo.

En este escrito intento transmitir a partir de un caso concreto que si el proceso formativo no contagia ganas de saber y amor por la profesión, si no profundiza lo bastante y no logra penetrar en las diversas subjetividades del alumnado, lo más probable es que, llegado el momento, los maestros noveles acudan a buscar puntos de referencia en su propia vida, en su recorrido escolar, en su modelo de educación. Y quizás, acomodados ahí, en lo sucesivo desconsideren la formación, cuando ha de ser una chispa provocadora y una fuente inagotable de aprendizaje y reflexión en este oficio de acompañar a otros a aprender, a relacionarse, a vivir.

Palabras clave: información inicial y permanente del profesorado; practicum; asesoramiento; práctica reflexiva

\section{ABSTRACT}

As is well known, initial teacher education is important and transformative for future teachers. It can be traversed going forward (in an open way to change and generating innovation) or looking back, repeating past practices that offer the security of the known, but not the advancement of the new. In this writing I try to convey from a concrete case that if the training process does not spread the desire to know and love for the profession; if it does not go deep enough and fails to penetrate the diverse subjectivities of the student body, it is most likely that, when the time comes, new teachers will come to look for points of reference in their own lives, 
Aprender a ser maestros es aprender a mirar a los niños, a estar con ellos, a acompañarlos, a comprenderlos, es enlazar el mundo afectivo con el del aprendizaje, es valorar el día a día, vincularse con los alumnos, implicarse desde adentro y apasionadamente. in their school journey, in their model of education. And perhaps, accommodated there, henceforth disregard training, when it has to be a provocative spark and an inexhaustible source of learning and reflection in this job of accompanying others to learn, to relate, to live.

Keywords: initial and permanent teacher training; practicum; counseling; reflective practice

Susi hizo las prácticas del Ciclo Formativo de Educación infantil en nuestra escuela. Tenía treinta años y había trabajado en algunas escuelas infantiles. Desde el principio se mostró activa, inquieta y curiosa. Participaba en todo, observaba, hablaba con las maestras, y preguntaba mucho. En una de las reuniones de seguimiento de las prácticas que hacíamos semanalmente con las cinco alumnas que recibíamos ese año (de Magisterio y del Ciclo), planteó algo que le había llamado la atención y quería que tratásemos.

Vio que un niño y una niña de cinco años estaban besándose en el patio y que las maestras no dijeron nada. Ni se acercaron, ni intervinieron, y eso le chocó sobremanera. Cuando lo explicó le pregunté qué se suponía que tenían que haber hecho las maestras. Y dijo que tendrían que haberles dicho:

- " $\mathrm{NNo}$ ! Eso no se hace."

- ¿Y por qué?, le insistía yo.

- Pues... no sé por qué, pero es lo que siempre he visto. Me lo han dicho a mi, he visto que se lo decían a otros niños y hasta yo misma lo he dicho.

- ¿Pero tú ves mal que se besen? ¿Por qué? ¿Qué crees que puede pasar si se les deja besarse? ¿No lo puedes contemplar como una muestra de cariño o como un tanteo propio del crecimiento?

Las chicas hablaron de sus vivencias y dijeron lo que les habían explicado en sus estudios sobre las manifestaciones tempranas de la sexualidad infantil, que era muy poco. "Sí, estudiamos lo de las etapas oral, anal y todo eso, y nos dijeron que había que decirles a los niños, si preguntaban, que los bebés nacían de las barrigas de las mamás. Pero nada más".

En sus experiencias de vida lo único que habían escuchado sobre estas cosas era que NO se podían hacer y que había que prohibir o distraer a los niños que las ha- 
cían, cuando no reñirlos abiertamente, así que respondían de la misma manera. Comentamos el significado de estas muestras tempranas de afecto y acercamiento corporal, poniendo ejemplos para ver si podían moverse desde su opinión de prohibición total a una postura más tolerante. El objetivo era ir planeando cuál podría ser en lo sucesivo su mirada, su actitud y su intervención en las ocasiones en las que vieran a los niños chuparse el dedo, masturbarse, mirar los genitales de otros, besarse, etc. El tema despertó resistencias, bastante susto y hasta cierto malestar. Tardamos unas cuantas semanas en lograr una actitud algo más abierta y flexible, aunque apenas era un empezar, que requeriría lecturas, reflexiones y más formación.

Posteriormente Susi trajo otra pregunta interesante: “¿Cómo puedo hacer yo para que los niños me hagan caso? Les llamo y me ignoran. En cambio les llaman sus maestras y les hacen caso". Hablamos entonces de la función del maestro, del significado de la ley, de normas, de autoridad, de confianza, de coherencia. Ellas se situaban en el lugar de alumnos y no en el de maestras, les costaba asumir que iban a estar al cargo de una clase, que se preparaban para cambiar de papel. Un nuevo asunto que requeriría continuar formándose.

Otro día Susi contó que en la clase en la que estaba le había dicho a una niña como alabanza, "campeona", y la maestra le había comentado que no hacía falta que la valorase mediante una palabra que evocaba la competición, el triunfo o la fuerza. Así que emprendimos el

\author{
Ellas se \\ situaban en el \\ lugar de alumnos \\ y no en el de \\ maestras, \\ les costaba \\ asumir que iban a \\ estar al cargo de \\ una clase, \\ que se \\ preparaban para \\ cambiar de papel.
}


